\title{
Virtual House Calls: Telemedicine and Reforming the Health Care Delivery Model with Strategies Implemented in a Novel Coronavirus Pandemic
}

$\mathrm{J}$ Gen Intern Med 35(7):2243

DOI: $10.1007 / \mathrm{s} 11606-020-05867-2$

(c) Society of General Internal Medicine 2020

$\mathrm{D}$ uring the pandemic caused by severe acute respiratory syndrome coronavirus 2 (Covid-19), the US Centers for Medicare and Medicaid expanded coverage to allow clinicians to temporarily see patients though telemedicine visits instead of traditional office visits ${ }^{1}$. Telemedicine has been a revolutionary tool for clinicians in this pandemic because it enabled continued medical care while maintaining social distancing and allowed patients who are at greater risk for morbidity and mortality from Covid-19 infection the ability to get medical assessments without leaving their homes ${ }^{1}$. With the utility of telemedicine being proven in this pandemic, it strengthens the argument that the utilization of telemedicine should be incorporated into routine medical care.

Traditional office visits can be difficult for patients and providers. For patients, office visits led to long commutes, wait times, and increased exposure to infectious diseases, with health care providers also at increased risk of infection ${ }^{2}$. Additionally, the routine physical examination, which is an integral part of a traditional office visit, often does not contribute to the medical plan. For example, annual physicals have been found to have no effect on total mortality, cancer mortality, and likely no effect on cardiovascular mortality or risk of strokes ${ }^{3}$. Studies found that the majority of diagnosis is attributed to the medical history and little from the physical exam ${ }^{4}$. Furthermore, telehealth visits can include focused physical examination maneuvers using image- and audiocapturing devices to assess the dermatologic, cardiac, and pulmonary systems ${ }^{2}$.

With risks of transmissible infections, like the annual influenza epidemic, which led to higher mortality rates than Covid19 at the time Covid-19 was declared pandemic, the benefits of telehealth should not be restricted after the Covid-19 pandemic ends. Through telehealth systems, it has been found that patients with chronic illnesses had better mortality, quality of life, and hospital readmission outcomes ${ }^{5}$. A study also found that $95 \%$ of patients who participated in a telehealth visit rated

Received April 9, 2020

Accepted April 16, 2020

Published online May 4, 2020 it as good as, if not better than, a traditional office visit ${ }^{2}$. It is now, in a time of crisis, that we should embrace innovation, not for just in this moment, but for the future. We must incorporate the technology that we have already leveraged, and further invest in novel approaches to improve the safety, experience, and capability of telehealth to optimize health care delivery without sacrificing quality. Though modern technology, doctors can again travel to patient homes with a modern version of a physician house call.

Acknowledgements: NK is supported by the Fogarty International Center of the National Institutes of Health (NIH) under award number D43TW009343 and the University of California Global Health Institute (UCGHI). JDK acknowledges funding from NIH P3OMH058107 (The Center for HIV Identification, Prevention, and Treatment Services) and NIH/NIAID AIO28697 (UCLA Center for AIDS Research).

Noah Kojima, $M D$

Jeffrey D Klausner, MD

Department of Medicine, University of California Los Angeles, Los Angeles, 90095, USA

Corresponding Author: Noah Kojima, MD; Department of Medicine, University of California Los Angeles, Los Angeles 90095, USA (e-mail: nkojima@ucla.edu).

\section{Compliance with Ethical Standards:}

Disclaimer: The content is solely the responsibility of the authors and does not necessarily represent the official views of the NIH or UCGHI.

Conflict of Interest: The authors declare that they do not have a conflict of interest.

\section{REFERENCES}

1. United States Centers for Medicare \& Medicaid Services. MEDICARE TELEMEDICINE HEALTH CARE PROVIDER FACT SHEET. In: S United States Centers for Medicare \& Medicaid Services, ed. Baltimore, MD: U.S. Centers for Medicare \& Medicaid Services; 2020.

2. Polinski JM, Barker T, Gagliano N, Sussman A, Brennan TA, Shrank WH. Patients' Satisfaction with and Preference for Telehealth Visits. J Gen Intern Med. 2016;31(3):269-275.

3. Krogsboll LT, Jorgensen KJ, Gotzsche PC. General health checks in adults for reducing morbidity and mortality from disease. Cochrane Database Syst Rev. 2019;1:CD009009.

4. Peterson MC, Holbrook JH, Von Hales D, Smith NL, Staker LV. Contributions of the history, physical examination, and laboratory investigation in making medical diagnoses. West J Med. 1992;156(2):163-165.

5. Totten AM, Womack DM, Eden KB, et al. Telehealth: Mapping the Evidence for Patient Outcomes From Systematic Reviews. Rockville (MD) 2016 .

Publisher's Note: Springer Nature remains neutral with regard to jurisdictional claims in published maps and institutional affiliations. 